\title{
The INO80 Family of Chromatin-Remodeling Enzymes: Regulators of Histone Variant Dynamics
}

\author{
S. Watanabe And C.L. Peterson \\ Program in Molecular Medicine, University of Massachusetts Medical School, Worcester, Massachusetts 01605 \\ Correspondence: craig.peterson@umassmed.edu
}

\begin{abstract}
The evolutionarily conserved INO80 family of ATP-dependent chromatin-remodeling enzymes has roles in many nuclear processes, including transcription, DNA repair, and DNA replication. Here, we discuss the in vivo and in vitro properties of these enzymes, focusing on recent studies which suggest that members of this family govern the deposition and removal of the histone variant H2A.Z.
\end{abstract}

Eukaryotic cells organize their genomic DNA within the tiny confines of the nucleus by compacting it into a proteinaceous structure called chromatin. The basic building block of chromatin is the nucleosome, which contains 147 base pairs of DNA wrapped in $\sim 1.7$ superhelical turns around a core histone octamer composed of two histone $\mathrm{H} 2 \mathrm{~A} / \mathrm{H} 2 \mathrm{~B}$ heterodimers and a histone $\mathrm{H} 3 / \mathrm{H} 4$ heterotetramer. Because nucleosome structure reduces the accessibility of DNA to factors involved in DNA metabolic processes (e.g., gene transcription, DNA repair, and DNA replication), cells have evolved several mechanisms to regulate chromatin structure.

The three primary regulators of chromatin dynamics are histone-modifying enzymes, histone variants, and ATPdependent chromatin-remodeling enzymes. Histone-modifying enzymes catalyze the posttranslational modification of histone residues, such as acetylation, methylation, sumolyation, ubiquitylation of lysines, or phosphorylation of serines and threonines. These modifications often exert biological function by influencing the chromatin binding of downstream effector proteins (Taverna et al. 2007). A small subset of histone modifications, however, directly influences the folding dynamics of chromatin fibers, and in some instances, they can have subtle effects on the structure of the nucleosome itself (Shogren-Knaak et al. 2006; Ferreira et al. 2007; Watanabe et al. 2010).

Chromatin structure and dynamics are also impacted by histone variants, exemplified by sequence isoforms of the core histones H2A and H3 (Talbert and Henikoff 2010). Histone variants, unlike the canonical histones, are expressed throughout the cell cycle, and they can be incorporated into chromatin in the absence of DNA replication. Histone $\mathrm{H} 2 \mathrm{~A}$ has the largest number of variants (macroH2A, H2A.X, H2A.Z, and H2A.bdb), and their incorporation into chromatin is linked to a variety of cellular activities, such as activation of transcription, DNA repair, heterochromatin formation, and mammalian X-chromosome inactivation.

ATP-dependent chromatin-remodeling enzymes use the energy from ATP hydrolysis to directly alter chromatin structure, catalyzing the "sliding" of histone octamers in cis along DNA, eviction of histone $\mathrm{H} 2 \mathrm{~A} / \mathrm{H} 2 \mathrm{~B}$ dimers, or ejection of an entire histone octamer (Clapier and Cairns 2009). In some cases, these enzymes can also remove one or both $\mathrm{H} 2 \mathrm{~A} / \mathrm{H} 2 \mathrm{~B}$ dimers from a nucleosome and replace it with different $\mathrm{H} 2 \mathrm{~A} / \mathrm{H} 2 \mathrm{~B}$ dimers, a reaction termed dimer exchange. ATP-dependent remodeling enzymes are typically multiprotein complexes, although some monomeric enzymes do exist (e.g., CHD1; Tran et al. 2000), and they are found in all eukaryotes. Each enzyme harbors a catalytic ATPase subunit that is a member of the Snf2/Swi2 subfamily of DNA-stimulated ATPases, and ATP-dependent chromatin-remodeling enzymes have been classified into 24 families based on phylogenetic sequence comparisons of their ATPase domains (Flaus et al. 2006).

This chapter focuses on the INO80 family of ATP-dependent remodeling enzymes. This group of enzymes is conserved in all eukaryotes examined to date, and they appear to have crucial roles in nearly all DNA metabolic processes, including gene transcription, DNA repair, and DNA replication. Members of this family have the unique ability to catalyze ATP-dependent histone dimer exchange reactions, thereby regulating the incorporation and dynamics of histone variants. Recent studies also suggest that the dimer exchange activity of INO80 family members may be regulated by histone posttranslational modifications, indicating a novel cooperation among all three factors that regulate chromatin dynamics.

\section{THE INO80 FAMILY OF REMODELING ENZYMES}

The INO80 family of remodeling enzymes is currently composed of two classes of enzymes, Ino80 and Swr1, purified from yeast, Drosophila, and mammalian cells. All organisms characterized to date contain one member of the Ino80 class of enzymes, whereas mammals appear to have at least two distinct remodeling enzymes that contain different ATPases of the Swr1 class, SRCAP and p400, with the p400 ATPase being the most diverged from yeast 
Swr1 (Fig. 1). The catalytic subunits of all INO80 family members contain a diagnostic Snf2/Swi2 ATPase domain that includes motifs I-VI common to the SF1 superfamily of DNA-stimulated ATPases and DNA helicases (Fig. 2). One defining characteristic of the INO80 family is the presence of a large insertion between motifs III and IV, creating a split ATPase domain. This insertion is relatively small for the yeast members (247-282 amino acids) but is $>1000$ amino acids for mammalian SRCAP. As described below, these extra amino acids are required for novel subunit-subunit interactions that are likely to provide unique activities to this group of enzymes. In addition to the ATPase domain, each enzyme also contains a highly conserved helicase-SANT-associated (HSA) domain that mediates interactions with actin-related protein (Arp) subunits (see below) (Szerlong et al. 2008), and the Drosophila Domino and mammalian p400 ATPases contain carboxy-terminal SANT domains that may provide a functional interaction with histone amino-terminal domains (Boyer et al. 2004). And finally, the mammalian

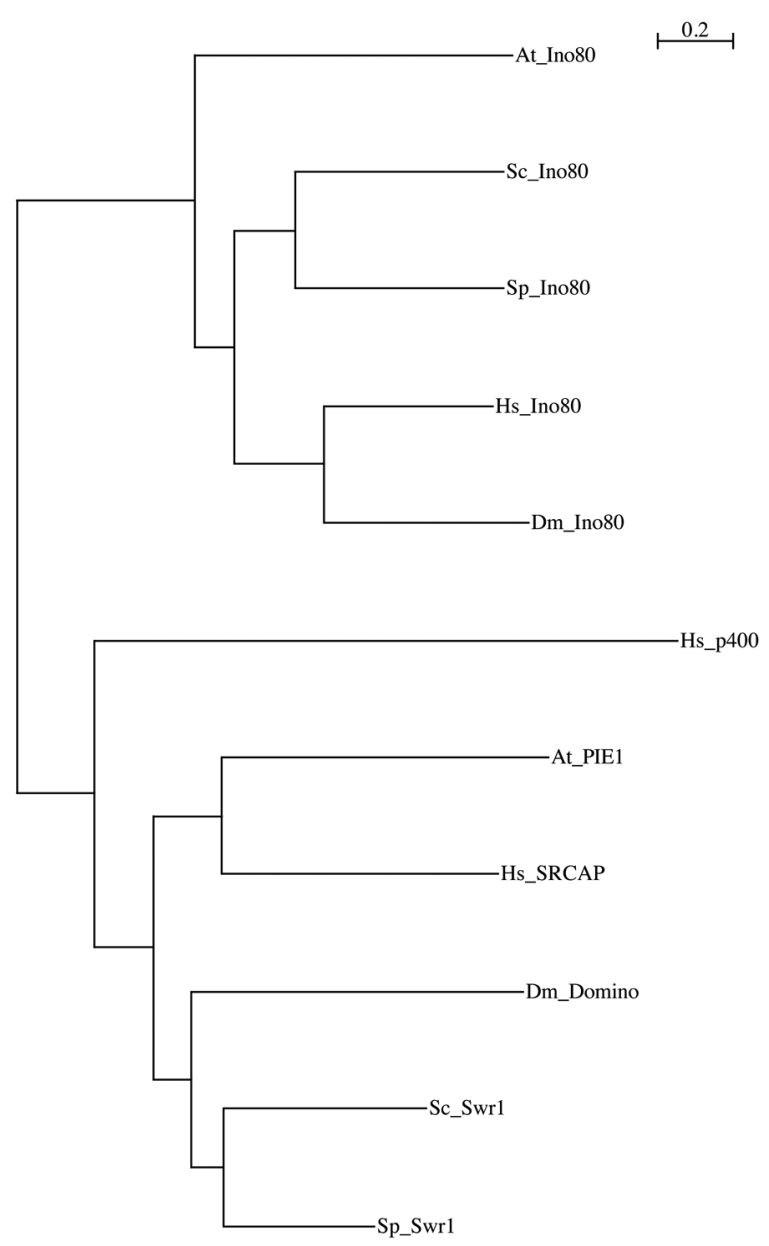

Figure 1. Phylogenetic tree of INO80 family. Multiple sequence alignment was performed with ClustalX software. Phylogenic tree was constructed with the PHYLIP suite software (neighbor, protdist, and Njplot). (At) Arabidopsis thaliana, (Dm) Drosophila melanogaster, (Hs) Homo sapiens, (Sc) Saccharomyces cerevisiae, (Sp) Schizosaccharomyces pombe.
SRCAP ATPase has a unique AT hook element that may provide additional DNA-binding activity.

All INO80 family members function within the context of large multisubunit complexes called INO80 and SWR$\mathrm{C}$, respectively, in yeast (Table 1). In the case of the yeast INO80 and SWR-C enzymes, the subunit composition and organization have an initial framework (Fig. 3). The yeast INO80 complex contains 15 subunits (Shen et al. 2003) and the SWR-C complex contains 14 (Mizuguchi et al. 2004). In addition to their related ATPase subunits, yeast INO80 and SWR-C remodeling enzymes share four additional subunits: Rvb1, Rvb2, Arp4, and actin. The Rvb1 and Rvb2 subunits are highly related $\mathrm{AAA}^{+}$ATPases that are essential for cell viability from yeast to man (Qiu et al. 1998; Kanemaki et al. 1999). They show sequence homology with the bacterial RuvB ATPase, which is believed to function as a Holliday junction resolvase during homologous recombination (Taylor 1992; Tsaneva et al. 1992). Bacterial RuvB forms a double hexomeric ring (Mitchell and West 1994; Stasiak et al. 1994) and, based on the stoichiometry of Rvb1 and Rvb2 within the SWR-C and INO80 complexes, is also likely to form hexamers. Deletions of the novel insertion element within the Ino80 or Swr1 ATPase domain leads to loss of both Rvb1 and Rvb2, suggesting that Rvb proteins interact with this portion of the ATPase domain (Wu et al. 2005).

The common Arp4 and actin subunits interact with the conserved HSA domain positioned amino terminus of the Ino80 or Swr1 ATPase domains (Fig. 3) (Szerlong et al. 2008). These subunits are members of the highly conserved actin superfamily of proteins that contains canonical actin as well as numerous Arps. Actin superfamily members share a common tertiary structure called the actin fold, which includes an ATP-binding pocket. However, only actin and Arp4 are known to bind ATP, although mutations within the putative Arp4 ATP-binding pocket do not appear to disrupt the function of INO80 or SWRC (Gorzer et al. 2003).

The INO80 and SWR-C complexes each harbor additional complex-specific Arp subunits: Arp5 and Arp8 within INO80, and Arp6 within SWR-C. For INO80, the Arp8 subunit also associates with the HSA domain (Szerlong et al. 2008), whereas the Arp5 subunit associates with Rvb1/Rvb2 within the ATPase insertion domain (Jonsson et al. 2004). In the case of the SWR-C complex, the Arp6 subunit interacts with the ATPase insertion domain (Wu et al. 2005). Although the precise function of actin and Arp subunits remains unknown, Arp4 and Arp8 are able to bind to core histones (Harata et al. 1999; Shen et al. 2003), suggesting that these Arps may function as histone chaperones during remodeling reactions. Furthermore, studies with the RSC remodeling enzyme indicate that interaction of Arp subunits with the HSA domains of Swi2/ Snf2 ATPases may have a general role in modulating the efficiency of ATP hydrolysis (Szerlong et al. 2008). Consistent with this view, INO80 complexes that lack Arp4 and Arp8 are crippled for ATP-dependent remodeling activity (Shen et al. 2003).

The SWR-C complex contains a second histone-binding subunit, Swc2. Swc2 is unique to SWR-C and contains a highly acidic domain within its amino terminus (1- 


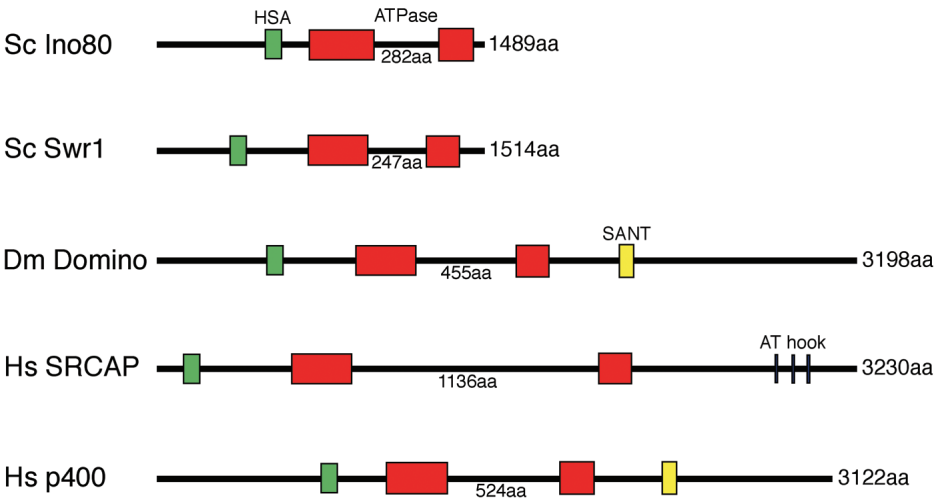

Figure 2. Domain structures of INO80 family members. Numbers at right represent amino acid length of proteins. Numbers between ATPase domains are amino acid length of unique insertions. (HSA) Helicase-SANT associated, (SANT) Swi3, Ada2, N-CoR, TFIIIB.

$\underline{\text { Table 1. Subunit Composition of INO80 Family Members }}$

\begin{tabular}{|c|c|c|c|c|c|c|c|c|}
\hline \multirow{2}{*}{$\frac{\text { Complex }}{\text { Function/ homology }}$} & \multicolumn{3}{|c|}{ INO80 } & \multirow{2}{*}{$\frac{\text { SWR-C }}{\text { Yeast }}$} & \multirow{2}{*}{$\frac{\text { SRCAP }}{\text { Human }}$} & \multirow{2}{*}{$\begin{array}{l}\text { dTip60 } \\
\text { Fly }\end{array}$} & \multirow{2}{*}{$\begin{array}{l}\text { TRRAP/ } \\
\text { Tip60/ } \\
\text { Human }\end{array}$} & \multirow{2}{*}{$\begin{array}{l}\text { NuA4 } \\
\text { Yeast }\end{array}$} \\
\hline & Yeast & Fly & Human & & & & & \\
\hline ATPase & Ino80 & INO80 & INO80 & Swr1 & SRCAP & Domino & p400 & \\
\hline RuvB-like & $\begin{array}{l}\text { Rvb1, } \\
\text { Rvb2 }\end{array}$ & $\begin{array}{l}\text { Reptin, } \\
\text { Pontin }\end{array}$ & $\begin{array}{l}\text { Tip49a, } \\
\text { Tip49b }\end{array}$ & $\begin{array}{l}\text { Rvb1, } \\
\text { Rvb2 }\end{array}$ & $\begin{array}{l}\text { Tip49a, } \\
\text { Tip49b }\end{array}$ & $\begin{array}{l}\text { Reptin, } \\
\text { Pontin }\end{array}$ & $\begin{array}{l}\text { Tip49a, } \\
\text { Tip49b }\end{array}$ & \\
\hline \multirow[t]{4}{*}{ Arp } & $\begin{array}{l}\text { Arp4, } \\
\text { ARp5, } \\
\text { Arp8 }\end{array}$ & $\begin{array}{l}\text { Arp5, } \\
\text { Arp8 }\end{array}$ & $\begin{array}{l}\text { Arp4, } \\
\text { Arp5, } \\
\text { Arp8 }\end{array}$ & $\begin{array}{l}\text { Arp4, } \\
\text { Arp6 }\end{array}$ & $\begin{array}{l}\text { Arp4, } \\
\text { Arp6 }\end{array}$ & Arp4 & Arp4 & Arp4 \\
\hline & Actin & Actin & Actin & Actin & & Actin & Actin & Actin \\
\hline & Ies 2 & & $\begin{array}{l}\text { Ies2/ } \\
\text { PAPA1 }\end{array}$ & & & & & \\
\hline & Ies6 & & Ies6 & & & & & \\
\hline $\begin{array}{l}\text { Gli-Kruppel zinc- } \\
\text { finger transcription } \\
\text { factor }\end{array}$ & $\begin{array}{l}\text { Iec1 } \\
\quad(S . \text { pombe })\end{array}$ & Pho & YY1 & & & & & \\
\hline $\begin{array}{l}\text { UCH family } \\
\text { deubiquitylating } \\
\text { enzyme }\end{array}$ & & Uch37 & Uch37 & & & & & \\
\hline $\begin{array}{l}\text { Nuclear factor related } \\
\text { to } \mathrm{kB} \text {-binding } \\
\text { protein }\end{array}$ & & $\mathrm{NFR} \kappa \mathrm{B}$ & NFR $\kappa \mathrm{B}$ & & & & & \\
\hline YEATS protein & Taf14 & & & Yaf9 & GAS41 & GAS41 & GAS41 & Yaf9 \\
\hline H2A.Z interaction & & & & Swc2 & YL-1 & YL-1 & YL-1 & \\
\hline $\begin{array}{l}\text { DNA methyl- } \\
\text { transferase } 1- \\
\text { associated protein }\end{array}$ & & & & $\begin{array}{l}\text { Swc4 } \\
\text { Swc6 }\end{array}$ & $\begin{array}{l}\text { DMAP1 } \\
\text { ZnF-HIT1 }\end{array}$ & DMAP1 & DMAP1 & Swc4 \\
\hline Bromodomain & & & & Bdf1 & $\operatorname{Brd8}$ & $\operatorname{Brd} 8$ & $\begin{array}{l}\text { TRCp120/ } \\
\text { Brd8 }\end{array}$ & \\
\hline HAT & & & & & & $\begin{array}{l}\text { Tip60 } \\
\text { Tra1 }\end{array}$ & $\begin{array}{l}\text { Tip60 } \\
\text { TRRAP }\end{array}$ & $\begin{array}{l}\text { Esa1 } \\
\text { Tra1 }\end{array}$ \\
\hline \multirow[t]{5}{*}{ Chromodomain } & & & & & & MRG15 & $\begin{array}{l}\text { MRG15, } \\
\text { MRGX }\end{array}$ & Eaf3 \\
\hline & & & & & & Eaf6 & FLJ11730 & Eaf6 \\
\hline & & & & & & MRGBP & MRGBP & Eaf7 \\
\hline & & & & & & $\mathrm{E}(\mathrm{Pc})$ & & Ep11 \\
\hline & & & & & & ING3 & ING3 & Yng2 \\
\hline Other subunits & $\begin{array}{l}\text { Nhp10, } \\
\text { Ies1, Ies3, } \\
\text { Ies4, Ies5, }\end{array}$ & & $\begin{array}{l}\text { Amida, } \\
\text { MCRS1, } \\
\text { FLJ20309, } \\
\text { FLJ90652 }\end{array}$ & $\begin{array}{l}\text { Swc3, } \\
\text { Swc5, } \\
\text { Swc7 }\end{array}$ & & & & $\begin{array}{l}\text { Eaf1, } \\
\text { Eaf5 }\end{array}$ \\
\hline
\end{tabular}


A Sc INO80

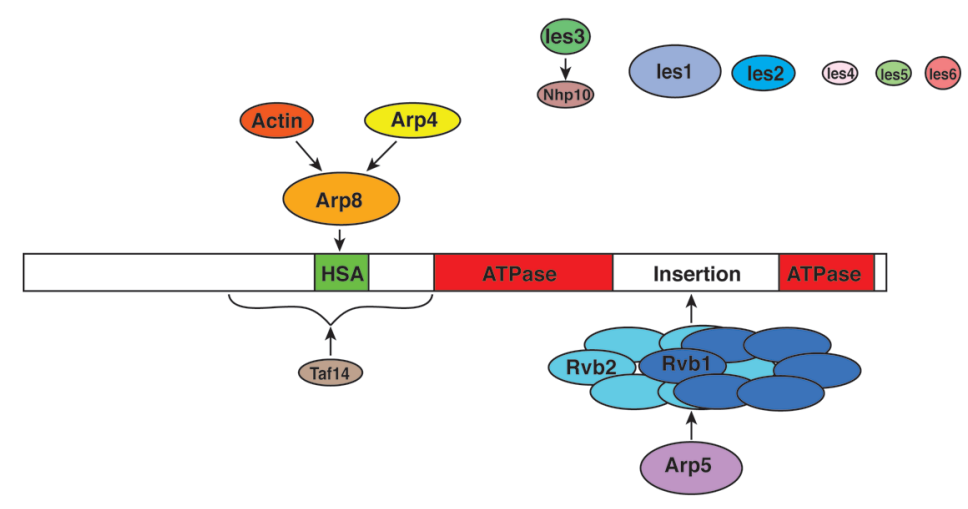

B Sc SWR-C

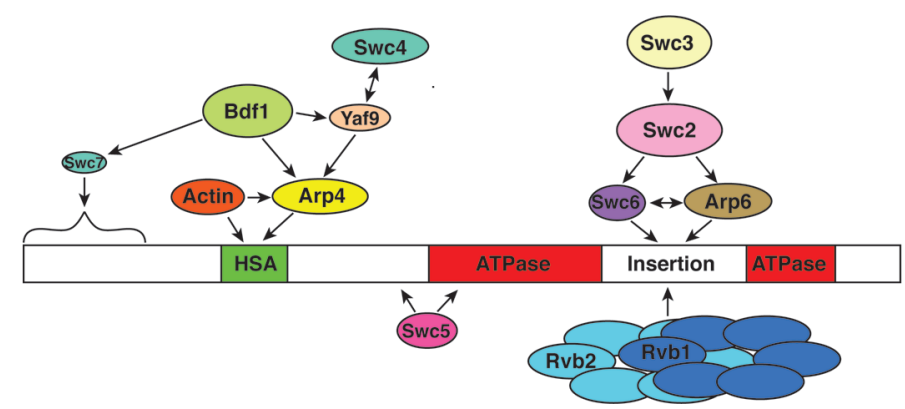

Figure 3. Subunit interactions of $(A)$ yeast INO80 and $(B)$ SWR-C. Arrows indicate that the interaction of a subunit with the complex requires the subunit to which the arrow points.

281aa) that binds to the histone H2A.Z variant (Wu et al. 2005). Its metazoan counterpart YL-1, which is found in the human SRCAP and Tip60 complexes, can also bind to H2A.Z (Wu et al. 2005). The Swc2 subunit associates with Swc6 and Arp6 subunits, forming a histone chaperone subcomplex that has an essential role in the chromatin-remodeling activities of SWR-C (Wu et al. 2005).

The human INO80 complex has a subunit composition similar to its yeast counterpart, with the notable exception that it contains the YY-1 zinc-finger DNA-binding transcription factor (Cai et al. 2007). Homologs of YY1 are also found in the Drosophila and $S$. pombe INO80 complexes (Pho and lec1, respectively) (Klymenko et al. 2006; Hogan et al. 2010). This subunit is likely to have key roles in the recruitment of Ino80 to target gene promoters (Cai et al. 2007). Drosophila and human INO80 complexes contain two additional metazoan-specific subunits: the deubiquitylating enzyme Uch37 and nuclear factor related (NFR) $\kappa \mathrm{B}(\mathrm{NFR}-\kappa \mathrm{B})$. Interestingly, Uch37 has been linked to interactions between INO80 and the $26 \mathrm{~S}$ proteasome (Yao et al. 2008).

Based on their subunit compositions (Table 1), the human SRCAP complex is likely to be the functional homolog of the yeast SWR-C complex. Interestingly, the subunit compositions of the Drosophila dTip60 complex and the mammalian TRRAP/Tip60 complexes suggest that they represent a combination of an SWR-C-like complex and an NuA4-like histone acetyltransferase complex. Fur- thermore, the Domino and p400 ATPases resemble a protein fusion between yeast Swr1 and Eaf1, a subunit of the yeast NuA4 histone acetyltransferase complex. Strikingly, Cote and colleagues have shown that a TRRAP/Tip60-like complex can be assembled in yeast cells simply by expression of an Swr1-Eaf1 fusion protein (Auger et al. 2008).

\section{SWR-C: A NOVEL CHROMATIN- REMODELING ENZYME}

Biochemical analyses of SWI/SNF and ISWI remodeling enzymes have led to the general view that chromatinremodeling enzymes engage a nucleosomal substrate and use the energy of ATP hydrolysis to translocate DNA over the histone octamer surface. This DNA translocation reaction leads to the "sliding" of the octamer in cis along DNA and might promote the eviction of histone dimers or the entire histone octamer. However, the purified SWR-C remodeling complex shows very poor DNA- or nucleosome-stimulated ATPase activity in vitro $(<10 \%$ the activity of SWI/SNF), and SWR-C is unable to mobilize nucleosomes in cis, even when high concentrations of enzymes are used in such assays (Mizuguchi et al. 2004; S Watanabe and CL Peterson, unpubl.). Indeed, SWR-C is the only member of the Swi2/Snf2 family of enzymes that cannot enhance restriction enzyme accessibility of nucleosomal arrays (Boyer et al. 2000; S Watanabe and CL Peterson, unpubl.). 
As is often the case, the key breakthrough in understanding how SWR-C might function came about from yeast genetics. Krogan and colleagues used synthetic genetic array (SGA) technology to systematically identify gene products involved in chromatin modification and RNA polymerase II (RNAPII) elongation (Krogan et al. 2003). Among the five genes identified in this screen was the gene encoding the H2A.Z histone variant (HTZ1) as well as three genes that were subsequently found to encode subunits of SWR-C. Furthermore, this study reported that an intact SWR-C complex is required for chromatin deposition of H2A.Z in vivo, and genetic analyses indicated that SWR-C and H2A.Z function together within the same pathway that regulates transcription and resistance to DNA-damaging agents and replication stress. Similar results were subsequently reported by the Rine and Madhani groups (Kobor et al. 2004).

These genetic studies suggested the possibility that SWR-C might catalyze a novel ATP-dependent histone H2A.Z deposition reaction. This prediction was confirmed by a set of elegant biochemical studies from $\mathrm{Wu}$ and colleagues (Mizuguchi et al. 2004). Indeed, rather than just directing the deposition of H2A.Z into chromatin, SWR$\mathrm{C}$ removes one or both $\mathrm{H} 2 \mathrm{~A} / \mathrm{H} 2 \mathrm{~B}$ dimers from a nucleosomal substrate and replaces them with an $\mathrm{H} 2 \mathrm{~A} . \mathrm{Z} / \mathrm{H} 2 \mathrm{~B}$ dimer(s) in an ATP-dependent reaction. This dimer exchange reaction requires the $\mathrm{H} 2 \mathrm{~A}$.Z-binding subunit of SWR-C (Swc2), and the reaction can be stimulated by acetylation of histone $\mathrm{H} 4$ and/or H2A within the nucleosomal substrate (Kusch et al. 2004; Altaf et al. 2010). Subsequent studies reported that the human SRCAP complex and human p400 complex exhibit similar biochemical activities (Ruhl et al. 2006; Gevry et al. 2007). Currently, it is not clear how yeast SWR-C or the mammalian counterparts catalyze the dimer exchange reaction. Does the enzyme translocate DNA like other SWI/SNF-like enzymes or does it function by a completely different mechanism? Does the enzyme require linker DNA or does it catalyze exchange on core nucleosome particles? How does the enzyme remove the $\mathrm{H} 2 \mathrm{~A} / \mathrm{H} 2 \mathrm{~B}$ dimer and ensure deposition of the $\mathrm{H} 2 \mathrm{~A} . \mathrm{Z} / \mathrm{H} 2 \mathrm{~B}$ dimer? Because SWR-C binds to the H2A.Z, how is the variant dimer "handed off" to the nucleosomal substrate? What makes SWR-C unique? How do the Arp and Swc subunits that are unique to the SWR$\mathrm{C}$ enzyme regulate its ATP-dependent activities? Hopefully, mechanistic studies will begin to address these key questions in the near future.

The H2A.Z histone variant occupies only a subset of yeast nucleosomes, with a preference for one to two nucleosomes that flank nucleosome-free regions upstream of genes transcribed by RNAPII (Guillemette et al. 2005; Raisner et al. 2005; Zhang et al. 2005; Albert et al. 2007). A similar enrichment is also seen at mammalian RNAPII promoters (Barski et al. 2007). Furthermore, yeast H2A.Z is enriched at nucleosomes that flank yeast centromeres and at the boundaries between heterochromatic and euchromatic regions. The location of H2A.Z-containing nucleosomes is mirrored by the localization of the SWR-C enzyme. Genome-wide analysis of yeast SWR-C localization shows a remarkable overlap with $\mathrm{H} 2 \mathrm{~A} . \mathrm{Z}$, with SWR-
C occupying most RNAPII promoters (Zhang et al. 2005). Similarly, mammalian p400 also colocalizes with H2A.Z at target promoters, and p400 is required for H2A.Z deposition in vivo (Gevry et al. 2007). Although it is not entirely clear how SWR-C is recruited to RNAPII promoters, it has been suggested that SWR-C might interact with DNA-binding transcription factors, such as Reb1 that has binding sites upstream of many RNAPII genes in yeast (Raisner et al. 2005). What is clear is that SWR-C localization requires histone acetylation by the NuA4 and SAGA (Spt-Ada-Gcn5-acetyltransferase) HAT complexes (Raisner et al. 2005; Zhang et al. 2005), and histone acetylation is likely to be recognized by the double bromodomain subunit of SWR-C, Bdf1. Thus, histone acetylation controls both the catalytic activity of SWR-C as well as its recruitment to target loci.

\section{INO80 AND SWR-C: FAMILY FEUD?}

Unlike the SWR-C enzyme, the yeast and human INO80 complexes have the hallmarks of "typical" remodeling enzymes. These enzymes have respectable ATPase activity that is stimulated by either DNA or nucleosomes, although the efficiency of ATP hydrolysis is $\sim 30 \%$ of that exhibited by SWI/SNF-like enzymes (Mizuguchi et al. 2004; S Watanabe and CL Peterson, unpubl.). Like other remodeling enzymes, yeast and human Ino80 can also use the energy of ATP hydrolysis to mobilize or "slide" nucleosomes along DNA in cis, and they can enhance the restriction enzyme accessibility of nucleosomal arrays (Shen et al. 2003; Jin et al. 2005; S Watanabe and CL Peterson, unpubl.). Ino80 tends to reposition mononucleosomes to the center of a DNA fragment, an activity reminiscent of ISWI-like enzymes (Shen et al. 2003; S Watanabe and CL Peterson, unpubl.). The directionality of this sliding reaction suggests that the interaction of Ino80 with its nucleosomal substrate may involve interactions with linker DNA, much like what is known for ISWI (Gangaraju and Bartholomew 2007).

The ATP-dependent mobilization of nucleosomes provides a likely mechanism for the role of INO80 in transcriptional regulation. The budding yeast INO80 gene was initially identified in a screen for mutants causing inositol auxotrophy (Ebbert et al. 1999), and subsequent genomewide transcription profiles revealed that Ino80 regulates $\sim 20 \%$ of genes in $S$. cerevisiae (Mizuguchi et al. 2004). INO80 is required for expression of several inducible genes, such as PHO5 and GAL1 (Ebbert et al. 1999), although INO80 is not essential for gene expression per se but, rather, controls the kinetics of induction (Barbaric et al. 2007; Ford et al. 2007). Likewise, the human Ino80 complex is recruited to the CDC6 and GRP78 genes where it controls their inducible expression (Cai et al. 2007). Although yeast INO80 action has been suggested to govern nucleosome loss at both active gene promoters and DNA double-strand breaks (DSBs) (see below), yeast INO80 does not show histone octamer eviction activity in vitro (S Watanabe and CL Peterson, unpubl.).

INO80 was one of the first chromatin-remodeling enzymes to be implicated in nuclear processes other than 
transcription (Shen et al. 2000). Whether Ino80 regulates these other functions solely via alterations in nucleosome positions is not known, although it seems unlikely. Yeast strains that lack INO80 are hypersensitive to DNA-damaging agents, such as methylmethane sulfonate, bleomycin, and ultraviolet (UV) light, as well as to the replication stress agent hydroxyurea (HU) (Shen et al. 2000). Likewise, depletion of Ino80 from human cells leads to sensitivity to topoisomerase inhibitors and UV irradiation ( $\mathrm{Wu}$ et al. 2007). Furthermore, depletion of human Ino80 or the YY1 subunit reduces the frequency of homologous recombination (HR) repair (Wu et al. 2007). A similar defect in HR has been observed in Arabidopsis mutants that lack INO80 (Fritsch et al. 2004). In yeast cells, the INO80 complex is recruited to sites of DNA DSBs via an interaction with DSB-induced $\mathrm{H} 2 \mathrm{~A}$ phosphorylation in surrounding chromatin (Morrison et al. 2004; van Attikum et al. 2004). In contrast to the case in human and plant cells, yeast INO80 does not appear to regulate the kinetics or efficiency of homologous recombination or nonhomologous end joining (Papamichos-Chronakis et al. 2006; van Attikum et al. 2007), although it does appears to be required for optimal rates of DSB processing (van Attikum et al. 2004, 2007).

What is clear is that Ino80 has a role in regulating the cell cycle checkpoint in response to a DSB, and this role is tightly linked to incorporation of the histone variant H2A.Z (Papamichos-Chronakis et al. 2006). In strains that harbor an amino-terminal deletion allele of INO80, the levels of H2A.Z in chromatin surrounding an unrepairable DSB increase precipitously. These aberrantly high levels of H2A.Z appear to block the ability of a cell to adapt to a persistent cell cycle checkpoint, because deletion of either SWR1 or HTZ1 (which encodes H2A.Z) restores checkpoint adaptation in the ino 80 mutant. These data were the first to suggest the possibility of an antagonistic relationship between INO80 and SWR-C.

Recent studies have also shown that the yeast INO80 complex has a crucial role in replication fork progression during DNA synthesis, especially under conditions of replication stress, such as when nucleotide pools are decreased by HU treatment (Papamichos-Chronakis and Peterson 2008; Shimada et al. 2008; Vincent et al. 2008). Genomewide analyses have shown that yeast Ino80 is bound to many replication origins even in the $G_{1}$ phase of the cell cycle, suggesting that INO80 may associate with the prereplicative complex (Shimada et al. 2008). Additional INO80 also appears to be recruited to replication forks if they are stalled within S phase. Strikingly, stalled replication forks are unstable in the absence of Ino80, and much of the replication machinery dissociates from the stalled fork, leading to an irreversible S-phase arrest (Papamichos-Chronakis and Peterson 2008; Shimada et al. 2008). Furthermore, Ino80 appears to collaborate with the ISW2 remodeling enzyme to control efficient fork progression even in the absence of replication stress (Vincent et al. 2008).

How does Ino80 govern replication fork progression and stability? Recent data indicate that this role, like the case for the response to DNA damage, is linked to the histone variant $\mathrm{H} 2 \mathrm{~A} . \mathrm{Z}$. Whereas $\mathrm{H} 2 \mathrm{~A}$. Z has a characteristic localization pattern in wild-type cells, H2A.Z is grossly mislocalized across the yeast genome in the absence of Ino80, with the overall pattern becoming more random (M Papamichos-Chronakis and CL Peterson, unpubl.). Importantly, Ino80 does not appear to control the amount H2A.Z deposited into chromatin but only its localization. Strikingly, the mislocalization of H2A.Z is tightly linked to the genome stability phenotypes of an ino80 mutant. For instance, depletion of H2A.Z alleviates the replication phenotypes of ino80, restoring fork progression in low concentrations of HU. Likewise, alterations in the aminoterminal domain of H2A.Z that mimic constitutive acetylation alleviate the sensitivity of ino80, arp5, and arp 8 mutants to DNA-damaging and replication stress agents.

These genetic studies suggest a model in which Ino80 protects genome integrity by catalyzing the ATP-dependent removal of unacetylated H2A.Z from chromatin that surrounds stalled replication forks or DSBs. Given the similarities between the Ino80 and Swr1 ATPases, and the fact that these remodeling complexes share several subunits, one plausible scenario is that INO80 also performs a dimer exchange reaction. However, in this case, INO80 may remove H2A.Z and incorporate H2A. Earlier studies by $\mathrm{Wu}$ and colleagues did test whether INO80 was capable of incorporating H2A.Z into chromatin, but it lacked robust activity in these assays (Mizuguchi et al. 2004). Recently, we found that INO80 can indeed incorporate H2A into recombinant yeast $\mathrm{H} 2 \mathrm{~A} . \mathrm{Z}$ mononucleosomes in an ATP-dependent reaction (S Watanabe and CL Peterson, unpubl.). In contrast, SWR-C, SWI/SNF, and RSC remodeling enzymes were inactive for H2A deposition. Furthermore, INO80 was unable to incorporate a new H2A/H2B dimer into an $\mathrm{H} 2 \mathrm{~A}$-containing nucleosome, indicating that INO80 shows specificity for an H2A.Z nucleosomal substrate. These biochemical studies are consistent with the idea that SWR-C and INO80 perform similar dimer exchange reactions but with opposing specificities (Fig. 4).

What makes members of the INO80/SWR1 family of enzymes uniquely able to perform dimer exchange reactions? One possibility is that dimer exchange activity is governed by subunits (e.g., Rvb1/Rvb2) that interact with the novel insertion domain located within the ATPase domain of Ino80 and Swr1. Consistent with this view, one recent study has reported that the human Rvb1/Rvb2 subunits of mammalian SWR-C-like complexes (Tip48/ Tip49) are sufficient to perform limited H2A.Z deposition in vitro (Choi et al. 2009). The significance of these studies should be viewed with caution, because other studies indicate that the mammalian p400 ATPase subunit is also sufficient for H2A.Z deposition in vitro (Gevry et al. 2007). Furthermore, work with yeast SWR-C has clearly shown that Swr1 and the Rvb1/Rvb2 subunits are not sufficient for H2A.Z deposition but that specific Arp and Swc subunits have key roles (Wu et al. 2005).

During the past few years, many studies have focused on the regulated deposition of histone variants, with work aimed at identifying specialized histone chaperones, deposition complexes, and ATP-dependent enzymes such as SWR-C. What is now becoming clear is that deposition of variants reflects only a small part of the dynamics that con- 


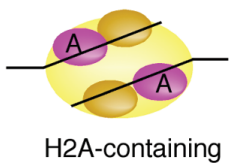

nucleosome

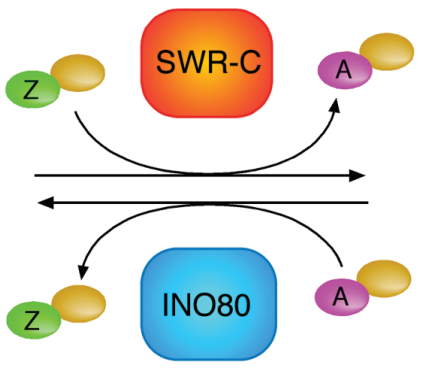

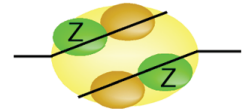

H2A.Z-containing nucleosome
Figure 4. Histone $\mathrm{H} 2 \mathrm{~A}$ variant exchange by INO80 and SWR-C. SWR-C deposits H2A.Z/ $\mathrm{H} 2 \mathrm{~B}$ dimers into an $\mathrm{H} 2 \mathrm{~A}$-containing nucleosome, and INO80 complex incorporates $\mathrm{H} 2 \mathrm{~A} / \mathrm{H} 2 \mathrm{~B}$ dimers into an H2A.Z-containing nucleosome, thus removing $\mathrm{H} 2 \mathrm{~A} . \mathrm{Z}$ from chromatin. trol histone variants. Enzymes such as INO80 appear to control the removal of the H2A.Z variant from chromatin and may globally control the inheritance of $\mathrm{H} 2 \mathrm{~A}$.Z as replication forks progress through parental H2A.Z nucleosomes. Most likely, enzymes such as INO80 will be targeted for regulation. Uncovering such regulatory events and dissecting how SWR-C and INO80-like enzymes work together to ensure proper levels and localization of H2A.Z will be the subject of intense research during the coming years.

\section{ACKNOWLEDGMENTS}

Our research is funded by grants from the National Institute of General Medical Sciences.

\section{REFERENCES}

Albert I, Mavrich TN, Tomsho LP, Qi J, Zanton SJ, Schuster SC, Pugh BF. 2007. Translational and rotational settings of H2A.Z nucleosomes across the Saccharomyces cerevisiae genome. $\mathrm{Na}$ ture 446: 572-576.

Altaf M, Auger A, Monnet-Saksouk J, Brodeur J, Piquet S, Cramet M, Bouchard N, Lacoste N, Utley RT, Gaudreau L, et al. 2010. NuA4-dependent acetylation of nucleosomal histones H4 and H2A directly stimulates incorporation of H2A.Z by the SWR1 complex. J Biol Chem 285: 15966-15977.

Auger A, Galarneau L, Altaf M, Nourani A, Doyon Y, Utley RT, Cronier D, Allard S, Cote J. 2008. Eaf1 is the platform for NuA4 molecular assembly that evolutionarily links chromatin acetylation to ATP-dependent exchange of histone $\mathrm{H} 2 \mathrm{~A}$ variants. Mol Cell Biol 28: 2257-2270.

Barbaric S, Luckenbach T, Schmid A, Blaschke D, Horz W, Korber P. 2007. Redundancy of chromatin remodeling pathways for the induction of the yeast PHO5 promoter in vivo. J Biol Chem 282: 27610-27621.

Barski A, Cuddapah S, Cui K, Roh TY, Schones DE, Wang Z, Wei G, Chepelev I, Zhao K. 2007. High-resolution profiling of histone methylations in the human genome. Cell 129: 823-837.

Boyer LA, Logie C, Bonte E, Becker PB, Wade PA, Wolffe AP, Wu C, Imbalzano AN, Peterson CL. 2000. Functional delineation of three groups of the ATP-dependent family of chromatin remodeling enzymes. J Biol Chem 275: 18864-18870.

Boyer LA, Latek RR, Peterson CL. 2004. The SANT domain: A unique histone-tail-binding module? Nat Rev Mol Cell Biol 5: $158-163$.

Cai Y, Jin J, Yao T, Gottschalk AJ, Swanson SK, Wu S, Shi Y, Washburn MP, Florens L, Conaway RC, et al. 2007. YY1 functions with INO80 to activate transcription. Nat Struct Mol Biol 14: 872-874.

Choi J, Heo K, An W. 2009. Cooperative action of TIP48 and TIP49 in H2A.Z exchange catalyzed by acetylation of nucleosomal H2A. Nucleic Acids Res 37: 5993-6007.

Clapier CR, Cairns BR. 2009. The biology of chromatin remodeling complexes. Annu Rev Biochem 78: 273-304.
Ebbert R, Birkmann A, Schuller HJ. 1999. The product of the SNF2/SWI2 paralogue INO80 of Saccharomyces cerevisiae required for efficient expression of various yeast structural genes is part of a high-molecular-weight protein complex. Mol Microbiol 32: 741-751.

Ferreira H, Somers J, Webster R, Flaus A, Owen-Hughes T. 2007. Histone tails and the $\mathrm{H} 3 \alpha \mathrm{N}$ helix regulate nucleosome mobility and stability. Mol Cell Biol 27: 4037-4048.

Flaus A, Martin DM, Barton GJ, Owen-Hughes T. 2006. Identification of multiple distinct Snf2 subfamilies with conserved structural motifs. Nucleic Acids Res 34: 2887-2905.

Ford J, Odeyale O, Eskandar A, Kouba N, Shen CH. 2007. A SWI/SNF- and INO80-dependent nucleosome movement at the INO1 promoter. Biochem Biophys Res Commun 361: 974-979.

Fritsch O, Benvenuto G, Bowler C, Molinier J, Hohn B. 2004. The INO80 protein controls homologous recombination in Arabidopsis thaliana. Mol Cell 16: 479-485.

Gangaraju VK, Bartholomew B. 2007. Dependency of ISW1a chromatin remodeling on extranucleosomal DNA. Mol Cell Biol 27: 3217-3225.

Gevry N, Chan HM, Laflamme L, Livingston DM, Gaudreau L. 2007. p21 transcription is regulated by differential localization of histone H2A.Z. Genes Dev 21: 1869-1881.

Gorzer I, Schuller C, Heidenreich E, Krupanska L, Kuchler K, Wintersberger U. 2003. The nuclear actin-related protein Act3p/Arp4p of Saccharomyces cerevisiae is involved in transcription regulation of stress genes. Mol Microbiol 50: 11551171.

Guillemette B, Bataille AR, Gevry N, Adam M, Blanchette M, Robert F, Gaudreau L. 2005. Variant histone H2A.Z is globally localized to the promoters of inactive yeast genes and regulates nucleosome positioning. PLoS Biol 3: e384.

Harata M, Oma Y, Mizuno S, Jiang YW, Stillman DJ, Wintersberger U. 1999. The nuclear actin-related protein of Saccharomyces cerevisiae, Act3p/Arp4, interacts with core histones. Mol Biol Cell 10: 2595-2605.

Hogan CJ, Aligianni S, Durand-Dubief M, Persson J, Will WR, Webster J, Wheeler L, Mathews CK, Elderkin S, Oxley D, et al. 2010. Fission yeast Iec1-ino80-mediated nucleosome eviction regulates nucleotide and phosphate metabolism. Mol Cell Biol 30: $657-674$.

Jin J, Cai Y, Yao T, Gottschalk AJ, Florens L, Swanson SK, Gutierrez JL, Coleman MK, Workman JL, Mushegian A, et al. 2005. A mammalian chromatin remodeling complex with similarities to the yeast INO80 complex. J Biol Chem 280: 41207-41212.

Jonsson ZO, Jha S, Wohlschlegel JA, Dutta A. 2004. Rvb1p/Rvb2p recruit Arp5p and assemble a functional Ino80 chromatin remodeling complex. Mol Cell 16: 465-477.

Kanemaki M, Kurokawa Y, Matsu-ura T, Makino Y, Masani A, Okazaki K, Morishita T, Tamura TA. 1999. TIP49b, a new RuvB-like DNA helicase, is included in a complex together with another RuvB-like DNA helicase, TIP49a. J Biol Chem 274: 22437-22444.

Klymenko T, Papp B, Fischle W, Kocher T, Schelder M, Fritsch C, Wild B, Wilm M, Muller J. 2006. A Polycomb group protein complex with sequence-specific DNA-binding and selective methyl-lysine-binding activities. Genes Dev 20: 1110-1122.

Kobor MS, Venkatasubrahmanyam S, Meneghini MD, Gin JW, 
Jennings JL, Link AJ, Madhani HD, Rine J. 2004. A protein complex containing the conserved Swi2/Snf2-related ATPase Swr1p deposits histone variant H2A.Z into euchromatin. PLoS Biol 2: E131.

Krogan NJ, Keogh MC, Datta N, Sawa C, Ryan OW, Ding H, Haw RA, Pootoolal J, Tong A, Canadien V, et al. 2003. A Snf2 family ATPase complex required for recruitment of the histone H2A variant Htz1. Mol Cell 12: 1565-1576.

Kusch T, Florens L, Macdonald WH, Swanson SK, Glaser RL, Yates JR III, Abmayr SM, Washburn MP, Workman JL. 2004. Acetylation by Tip60 is required for selective histone variant exchange at DNA lesions. Science 306: 2084-2087.

Mitchell AH, West SC. 1994. Hexameric rings of Escherichia coli RuvB protein. Cooperative assembly, processivity and ATPase activity. J Mol Biol 243: 208-215.

Mizuguchi G, Shen X, Landry J, Wu WH, Sen S, Wu C. 2004. ATP-driven exchange of histone $\mathrm{H} 2 \mathrm{AZ}$ variant catalyzed by SWR1 chromatin remodeling complex. Science 303: 343-348.

Morrison AJ, Highland J, Krogan NJ, Arbel-Eden A, Greenblatt JF, Haber JE, Shen X. 2004. INO80 and $\gamma-H 2 A X$ interaction links ATP-dependent chromatin remodeling to DNA damage repair. Cell 119: 767-775.

Papamichos-Chronakis M, Peterson CL. 2008. The Ino80 chromatin-remodeling enzyme regulates replisome function and stability. Nat Struct Mol Biol 15: 338-345.

Papamichos-Chronakis M, Krebs JE, Peterson CL. 2006. Interplay between Ino80 and Swr1 chromatin remodeling enzymes regulates cell cycle checkpoint adaptation in response to DNA damage. Genes Dev 20: 2437-2449.

Qiu XB, Lin YL, Thome KC, Pian P, Schlegel BP, Weremowicz S, Parvin JD, Dutta A. 1998. An eukaryotic RuvB-like protein (RUVBL1) essential for growth. J Biol Chem 273: 2778627793.

Raisner RM, Hartley PD, Meneghini MD, Bao MZ, Liu CL, Schreiber SL, Rando OJ, Madhani HD. 2005. Histone variant H2A.Z marks the $5^{\prime}$ ends of both active and inactive genes in euchromatin. Cell 123: 233-248.

Ruhl DD, Jin J, Cai Y, Swanson S, Florens L, Washburn MP, Conaway RC, Conaway JW, Chrivia JC. 2006. Purification of a human SRCAP complex that remodels chromatin by incorporating the histone variant H2A.Z into nucleosomes. Biochemistry 45: 5671-5677.

Shen X, Mizuguchi G, Hamiche A, Wu C. 2000. A chromatin remodelling complex involved in transcription and DNA processing. Nature 406: 541-544.

Shen X, Ranallo R, Choi E, Wu C. 2003. Involvement of actin-related proteins in ATP-dependent chromatin remodeling. Mol Cell 12: 147-155.

Shimada K, Oma Y, Schleker T, Kugou K, Ohta K, Harata M, Gasser SM. 2008. Ino80 chromatin remodeling complex promotes recovery of stalled replication forks. Curr Biol 18: 566575.

Shogren-Knaak M, Ishii H, Sun JM, Pazin MJ, Davie JR, Peterson CL. 2006. Histone H4-K16 acetylation controls chromatin struc- ture and protein interactions. Science 311: 844-847.

Stasiak A, Tsaneva IR, West SC, Benson CJ, Yu X, Egelman EH. 1994. The Escherichia coli RuvB branch migration protein forms double hexameric rings around DNA. Proc Natl Acad Sci 91: 7618-7622.

Szerlong H, Hinata K, Viswanathan R, Erdjument-Bromage H, Tempst P, Cairns BR. 2008. The HSA domain binds nuclear actin-related proteins to regulate chromatin-remodeling ATPases. Nat Struct Mol Biol 15: 469-476.

Talbert PB, Henikoff S. 2010. Histone variants: Ancient wrap artists of the epigenome. Nat Rev Mol Cell Biol 11: 264-275.

Taverna SD, Li H, Ruthenburg AJ, Allis CD, Patel DJ. 2007. How chromatin-binding modules interpret histone modifications: Lessons from professional pocket pickers. Nat Struct Mol Biol 14: $1025-1040$.

Taylor AF. 1992. Movement and resolution of Holliday junctions by enzymes from E. coli. Cell 69: 1063-1065.

Tran HG, Steger DJ, Iyer VR, Johnson AD. 2000. The chromo domain protein chd1p from budding yeast is an ATP-dependent chromatin-modifying factor. EMBO J 19: 2323-2331.

Tsaneva IR, Muller B, West SC. 1992. ATP-dependent branch migration of Holliday junctions promoted by the RuvA and RuvB proteins of E. coli. Cell 69: 1171-1180.

van Attikum H, Fritsch O, Hohn B, Gasser SM. 2004. Recruitment of the INO80 complex by H2A phosphorylation links ATP-dependent chromatin remodeling with DNA double-strand break repair. Cell 119: 777-788.

van Attikum H, Fritsch O, Gasser SM. 2007. Distinct roles for SWR1 and INO80 chromatin remodeling complexes at chromosomal double-strand breaks. EMBO J 26: 4113-4125.

Vincent JA, Kwong TJ, Tsukiyama T. 2008. ATP-dependent chromatin remodeling shapes the DNA replication landscape. Nat Struct Mol Biol 15: 477-484.

Watanabe S, Resch M, Lilyestrom W, Clark N, Hansen JC, Peterson C, Luger K. 2010. Structural characterization of H3K56Q nucleosomes and nucleosomal arrays. Biochim Biophys Acta 1799: 480-486.

Wu WH, Alami S, Luk E, Wu CH, Sen S, Mizuguchi G, Wei D, Wu C. 2005. Swc2 is a widely conserved H2AZ-binding module essential for ATP-dependent histone exchange. Nat Struct Mol Biol 12: 1064-1071.

Wu S, Shi Y, Mulligan P, Gay F, Landry J, Liu H, Lu J, Qi HH, Wang W, Nickoloff JA, et al. 2007. A YY1-INO80 complex regulates genomic stability through homologous recombinationbased repair. Nat Struct Mol Biol 14: 1165-1172.

Yao T, Song L, Jin J, Cai Y, Takahashi H, Swanson SK, Washburn MP, Florens L, Conaway RC, Cohen RE, et al. 2008. Distinct modes of regulation of the Uch37 deubiquitinating enzyme in the proteasome and in the Ino80 chromatin-remodeling complex. Mol Cell 31: 909-917.

Zhang H, Roberts DN, Cairns BR. 2005. Genome-wide dynamics of Htz1, a histone H2A variant that poises repressed/basal promoters for activation through histone loss. Cell 123: 219 231. 


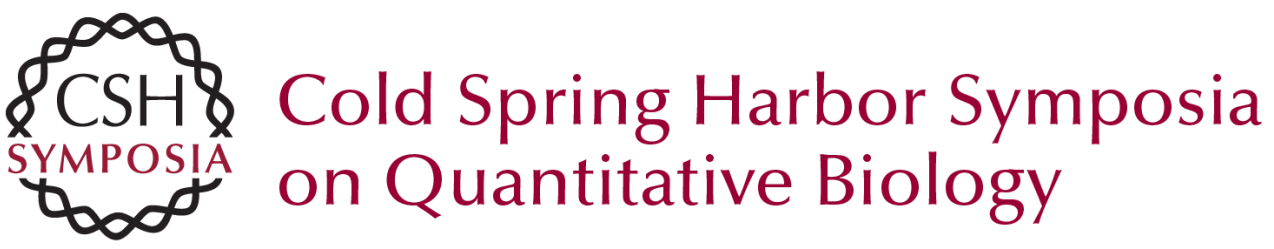

\section{The INO80 Family of Chromatin-Remodeling Enzymes: Regulators of Histone Variant Dynamics}

S. Watanabe and C.L. Peterson

Cold Spring Harb Symp Quant Biol 2010 75: 35-42 originally published online April 18, 2011 Access the most recent version at doi:10.1101/sqb.2010.75.063

References This article cites 55 articles, 19 of which can be accessed free at: http://symposium.cshlp.org/content/75/35.full.html\#ref-list-1

License

Email Alerting Receive free email alerts when new articles cite this article - sign up in Service the box at the top right corner of the article or click here. 